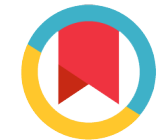

Check for updates

\section{The effect of using pre-operative ketamine injection on post-tonsillectomy pain intensity in children}

\section{Gholamali Dashti Khavidaki', Aliakbar Keykha², Faranak Beirami³, Masoum Khoshfetrat4,* (D), Fahimeh Shirazian 5}

\author{
${ }^{1}$ Assistant Professor, Department of Otolaryngology, Zahedan University of Medical \\ Sciences, Zahedan, Iran \\ ${ }^{2} \mathrm{MSc}$ in Critical Care Nursing, Community Nursing Research Center, Zahedan University \\ of Medical Sciences, Zahedan, Iran \\ ${ }_{3}^{3} \mathrm{MD}$, Department of Anaesthesiology and Critical Care, Khatam al-Anbia Hospital, \\ Zahedan University of Medical Sciences, Zahedan, Iran \\ ${ }^{4} \mathrm{MD}, \mathrm{FCCM}$, Department of Anaesthesiology and Critical Care, Khatam al-Anbia \\ Hospital, Zahedan University of Medical Sciences, Zahedan, Iran \\ 5MD, Zahedan University of Medical Sciences, Zahedan, Iran
}

\section{* For correspondence:}

Drkhoshfetrat@yahoo.com

Competing interests: The authors declare that no competing interests exist.

Received: 30 December 2017 Accepted: 25 January 2018 Published: 26 February 2018

Copyright The Author(s) 2018. This article is published with open access by BioMedPress.

This article is distributed under the terms of the Creative Commons Attribution License (CC-BY 4.0) which permits any use, distribution, and reproduction in any medium, provided the original author(s) and the source are credited.

\section{Abstract}

Introduction: Tonsillectomy in children is associated with some major complications originating from intense post-tonsillectomy pain which can distress patients, cause swallowing difficulties and discomfort, and also lead to aspiration. Thus, this study aimed to investigate the effect of using preoperative ketamine injection on post-tonsillectomy pain intensity in children. Methods: This double-blind clinical trial was carried out on 60 patients undergoing elective tonsillectomy. To this end, all the patients were anaesthetized by the same method. In the first group, 2 cc of ketamine $10.5 \mathrm{mg} /$ $\mathrm{kg}$ ) solution was topically injected into the soft tissue of tonsillar fossa (peritonsillar space); in the second group, a similar administration was performed but with normal saline. For all the patients, incision was made 5 minutes after injection with the Blast Dissection Snare method. Moreover, the patients' pain intensity and analgesics consumption were measured 30 minutes, and 1, 2, 4, and 6 hours after surgery. Finally, the collected data were analyzed using the SPSS software. Results: The present study was conducted on 60 patients, 37 males and 23 females, with the mean age of $9.3 \pm 3.4$ years. 
In this respect, repeated measures analysis of variance of patients' pain scores collected in five post-operative stages showed that pain intensity in both groups was at the highest level immediately after operation; it gradually decreased during measurement stages. However, at each measurement, the pain intensity experienced in the ketamine-treated group was significantly lower than that for the placebo group. Conclusion: It was concluded that preincision topical injection of ketamine can serve as an effective method to control post-tonsillectomy throat pain.

\section{Keywords}

Ketamine, Pain, Tonsillectomy

\section{Introduction}

Tonsillectomy is known as a surgical operation commonly performed in children. After tonsillectomy, these patients may experience numerous problems including bleeding, laryngospasm, pain, airway obstruction, nausea, vomiting, and aspiration (Dal et al., 2007). Typically, the most common post-operative effect of tonsillectomy in children is pain (Hanss et al., 2011; Shoar et al., 2012) which is difficult to control both at the hospital and home (Hamunen and Kontinen, 2005). This pain may interfere with oral food intake and also delay patient recovery (Giannoni et al., 2001; Hamunen and Kontinen, 2005), and consequently lead to prolonged hospitalization and significant financial burden (Aydin et al., 2007; Javid et al., 2012). Accordingly, there are several ways to control post-operative pain. The typical way of dealing with this issue is to administer non-steroidal analgesics and opioids; each method has its own merits and side effects. Opioids may lead to excessive relaxation and weakness of superior airway muscle, swallowing difficulties, respiratory distress, nausea, vomiting, and aspiration, while non-steroidal analgesics may increase the risk of bleeding, vomiting, and nausea (M?iniche et al., 2003; Safavi et al., 2009; Warncke et al., 1997).

An alternative way to cope with post-operative pain is the topical administration of analgesics to oropharyngeal space so as to minimize the systemic effects. In this regard, ketamine is one of the medications used for such pain relief. For this purpose, the oral cavity needs to be rinsed with ketamine-containing solution (Slatkin and Rhiner, 2003). Ketamine is similarly known to have desirable analgesic effects and can decrease swallowing-evoked pain after the operation if used before or during tonsillectomy (Elhakim et al., 2003; O'Flaherty and Lin, 2003). Studies in this domain have shown that ketamine has no hemodynamic and respiratory side effects (Javid and Khademian, 2016) and can also be 
administered by subcutaneous intravenous injection and spraying. However, the efficacy of these methods needs to be further investigated (Javid et al., 2012; Kimiaei Asadi et al., 2016). On this basis, this study aimed to investigate the effect of using pre-operative ketamine injection on post-tonsillectomy pain intensity in children.

\section{Materials-Methods}

This double-blind clinical trial was carried out on 60 patients aged 5-15 years who had been admitted for elective tonsillectomy. The research was approved by the Vice Chancellor's Office for Research and Technology and the Ethics Committee of Zahedan University of Medical Sciences in Zahedan, Iran. Prior to this study, informed consent of the patients' legal guardians was obtained. Following the precedents of similar studies, sample size was computed by $n=60$ (Pirzadeh et al., 2012).

The inclusion criteria included being in the age range of 5-15 years, being in ASA-class I, being a candidate for elective tonsillectomy, as well as having no records of endocrine disorders (diabetes, thyroid disorders, and adrenal insufficiency), congenital heart disease, bleeding disorders, cerebral palsy (CP), or psychiatric disorders.

On the other hand, the exclusion criteria included revocation of consent by the patients' legal guardians, any localized bleeding requiring intervention, as well as absence of airway disorders in need of intubation. Patients were also randomly assigned into two groups of 30 subjects, with one group receiving ketamine and the other receiving placebo. One day before the surgery, patients and their parents were trained on how to use the Visual Analog Scale to rate their pain. Within this pain reporting instrument, patients could rate pain intensity from 0 (representing no pain) to 10 (representing intolerable pain).

Before surgery, patients were pre-oxygenated with 100\% oxygen for 3 minutes, and then injected with midazolam $(0.05 \mathrm{mg} / \mathrm{kg})$. Anesthesia induction continued with the injection of fentanyl $(2 \mu \mathrm{g} / \mathrm{kg})$ and propofol $(2 \mathrm{mg} / \mathrm{kg})$. To facilitate the intubation, all patients received cisatracurium $(0.15 \mathrm{mg} / \mathrm{kg})$. After fixing the tracheal tube, anesthesia was maintained with $60 \%$ nitrous oxide in combination with oxygen and propofol (50-150 micrograms per kilogram). All the patients were operated by the same surgeon. Before incision, depending on the group, either 2 cc of pre-prepared ketamine $(0.5 \mathrm{mg} / \mathrm{kg})$ solution or the same amount of placebo (normal saline) solution was topically administered to the soft tissue of the tonsillar fossa. After 5 minutes, an incision was made using the Blast Dissection Snare method. Hemostasis was also achieved with two groups of sutures. After the operation and the reversal of anesthesia, patients were extubated and transferred to the recovery ward. In this ward, each patient's pain 
was assessed immediately after surgery, and 1, 2, 4, and 6 hours later. These assessments were made by a nurse (blinded to the patient group) using the Visual Analog Scale. In this respect, the patients with a pain score of more than 3 on this scale received $0.1 \mathrm{mg} / \mathrm{kg}$ of methadone via intramuscular injection. Accordingly, the amounts and the times of methadone injections were recorded on a pre-designed form. The patients with post-operative complications were excluded from the study. Moreover, the patients who did not exhibit any complications were discharged after 24 hours.

The collected data were then analyzed using descriptive statistics, Chi-square test, independent t-test, and repeated measures analysis of variance in the SPSS software.

\section{Results}

The study was conducted on 60 patients, 37 males and 23 females, with the mean age of $9.3 \pm 3.4$ years. In the ketamine group, 18 patients were male and 12 patients were female; there were 19 and 11 male and female patients in the placebo group, respectively. No significant difference was reported between the two groups in terms of gender $(p=0.698)$. Moreover, the mean age of patients in the ketamine group was $7.8 \pm 2.8$ years; the mean age in the placebo group was $8.8 \pm 3.6$ years. The results of the independent $t$-test showed no significant difference between both groups in terms of age $(p=0.946)$. Repeated measures analysis of variance of patients' pain scores collected in five post-operative stages also suggested that pain intensity in both groups was at the highest level immediately after operation and gradually decreased over measurement stages. However, the pain intensity experienced in the ketamine-receiving group was significantly lower than that in the placebo group (Table 1).

\section{Table 1. Mean scores of pain in the ketamine- and placebo-treated groups at different measurement stages}

\begin{tabular}{|c|c|c|c|c|c|c|c|c|c|c|}
\hline \multicolumn{9}{|c|}{ VAS mean score \pm SD } \\
\hline $\begin{array}{c}30 \text { minutes } \\
\text { after } \\
\text { surgery }\end{array}$ & $\begin{array}{c}\text { Group } \\
\text { size }\end{array}$ & Group & $P$ & $\begin{array}{c}1 \text { hour } \\
\text { after } \\
\text { surgery }\end{array}$ & $P$ & $\begin{array}{c}2 \text { hours } \\
\text { after } \\
\text { surgery }\end{array}$ & $P$ & $\begin{array}{c}4 \text { hours } \\
\text { after } \\
\text { surgery }\end{array}$ & $\begin{array}{c}\text { P hours } \\
\text { after } \\
\text { surgery }\end{array}$ \\
\hline Ketamine & 30 & $6.5 \pm 2.51$ & & $4.65 \pm 1.58$ & & $3.86 \pm 1.84$ & $2.81 \pm 1.45$ & $2.03 \pm 0.8$ \\
\hline Placebo & 30 & $7.62 \pm 1.97$ & 0.002 & $6.81 \pm 2.21$ & 0.000 & $4.93 \pm 0 / 80$ & & $4.5 \pm 1.85$ & $3.001 \pm 0.45$ & 0.000 \\
\hline
\end{tabular}


Comparison of opioid use in the two groups revealed that, at each measurement stage, the ketamine group needed significantly lower levels of opioid administration (Table 2).

Table 2. Opioid consumption in the ketamine- and placebo-treated groups at different measurement stages

\begin{tabular}{|c|c|c|c|c|c|c|c|c|c|c|c|}
\hline \multicolumn{12}{|c|}{ Number of patients in need of opioid injection } \\
\hline Group & Group size & $\begin{array}{c}30 \text { minutes } \\
\text { after } \\
\text { surgery }\end{array}$ & $\mathrm{P}$ & $\begin{array}{l}1 \text { hour } \\
\text { after } \\
\text { surgery }\end{array}$ & $\mathrm{P}$ & $\begin{array}{c}2 \text { hours } \\
\text { after } \\
\text { surgery }\end{array}$ & $P$ & $\begin{array}{l}4 \text { hours } \\
\text { after } \\
\text { surgery }\end{array}$ & $\mathrm{P}$ & $\begin{array}{l}6 \text { hours } \\
\text { after } \\
\text { surgery }\end{array}$ & $\mathrm{P}$ \\
\hline Ketamine & 30 & 8 & \multirow{2}{*}{0.000} & 6 & \multirow{2}{*}{0.000} & 3 & \multirow{2}{*}{0.001} & 1 & \multirow{2}{*}{0.003} & 0 & \multirow{2}{*}{0.04} \\
\hline Placebo & 30 & 14 & & 12 & & 9 & & 5 & & 2 & \\
\hline
\end{tabular}

\section{Discussion}

The results of this study showed that pre-incision topical administration of ketamine to tonsillar fossa could significantly reduce the post-operative incisionevoked pain and the amount of opioid needed to control it. As a result, this intervention could mitigate opioid-use-induced complications. Peripherally administered NMDA receptor antagonists have been also reported to be effective in anti-nociception (Carlton and Coggeshall, 1999; Carlton et al., 1998). Peripherally administered ketamine can similarly inhibit the development of post-operative pain (Warncke et al., 1997). It should be noted that the use of low dosage $(0.5 \mathrm{mg} / \mathrm{kg})$ of topically-injected ketamine in this study had no effect on the depth and the duration of patients' anesthesia. However, it was effective in controlling pain in patients.

In a research by Jahromi et al. on the analgesic effects of lidocaine, ketamine and morphine sprays on post-tonsillectomy pain, the pain scores resulting from all three interventions were lower than those in the control group although their pain measurement intervals were not the same as those in the present study. In that research study, pain was measured immediately after surgery and 20, 40 and 60 minutes later, and it was reported that at the 20-minute mark, pain score was at the lowest rate in the lidocaine group. Moreover, there was no statistical difference between the intervention groups at the 40-minute mark. Finally, at the 60-minute mark, pain scores were at the lowest level in the ketamine and morphine groups, which is consistent with the results of the present study. It was also observed that pain control effects of topical ketamine were persistent, as the pain scores of the intervention groups remained consistently lower than those in the control group. However, this could not be explicitly attributed to pain control ability of the drug since it is normal for pain intensity to decrease 
with time and also since pain expression is subjective and may vary from person to person (Hosseini Jahromi et al., 2012). Moreover, in the study by Eghbal et al., on the effects of intravenous injection of ketamine on post-tonsillectomy pain, it was reported that patients who had received ketamine before surgery had lower post-operative pain and a significantly lower need for paracetamol injection for pain control. In that study, pain was measured by Wong-Baker FACES Pain Rating Scale, in which patients did not express the level of pain but a score was given for each patient based on their facial expressions.

In spite of differences in ketamine administration technique and pain assessment method, the results of the present study were generally consistent with the results of the investigation by Eghbal et al. (Eghbal et al., 2013). Furthermore, Javid et al. compared the effects of intravenous and subcutaneous injections of ketamine, versus placebo (saline), in different groups using similar methods to the one in the present study and found that pain was significantly lower in the ketamine groups than in the placebo ones; no significant difference was found between both ketamine groups. However, the pain assessment method of that study was different from that employed in the present study, as they used Modified CHEOPS Pain Scoring method. In this method, crying, facial expressions, pain expressions, leg positions, and positions in bed were given a score between zero and two, and finally the level of pain was expressed as the sum of scores which ranged from zero to ten (Javid et al., 2012).

In a study by Asadi et al., two groups of patients receiving the same dose of acetaminophen 15 minutes before surgery and every 6 hours after surgery up to 24 hours were examined. However, the first dose of acetaminophen was supplemented with the injection of ketamine in one group and the injection of placebo in the other group. Pain intensity was also measured up to 12 hours after the operation and it was reported that, at half an hour and 6 hours after the operation, the ketamine group had experienced significantly lower pain intensity than that by the placebo group; however, there was no significant difference between both groups at the 12-hour mark. The major differences of that study with the present one were the methods of ketamine administration, pain measurement times, and pain measurement methods (they used CHEOPS Pain Scoring method) (Kimiaei Asadi et al., 2016). In a study by Canbay et al., the effects of topical morphine and topical ketamine on post-tonsillectomy pain intensity were compared. In that study, patients were divided into four groups to receive (i) ketamine in $10 \mathrm{cc}$ of artificial saliva, (ii) morphine in $5 \mathrm{cc}$ of artificial saliva, (iii) ketamine+morphine in $5 \mathrm{cc}$ of artificial saliva, and (iv) only $10 \mathrm{cc}$ of artificial saliva, in their tonsillar fossae. The study reported higher pain intensity and analgesic consumption in the control group. It was also revealed that the analgesic effects of morphine and ketamine could last longer when they were administered alone and not in combination (Canbay et al., 2008). In a study by Ayatollahi et al. on post-tonsillectomy pain relief effects of tramadol and topical ketamine, it was similarly reported that tramadol had a much better analgesic effect than ketamine (Ayatollahi et al., 2012). 


\section{Conclusion}

In the present study, topically administered ketamine could reduce posttonsillectomy pain intensity. However, determining whether this is the best medicine or method for this purpose requires further investigations.

\section{Acknowledgements}

This paper was a part of a dissertation submitted in partial fulfillment of the requirements for the completion of General Medicine. The article was funded and registered by the Vice-Chancellor's Office for Research and Technology at Zahedan University of Medical Sciences. The authors hereby express sincere gratitude to the head and staff of the University's Vice-Chancellor's Office for Research and Technology, and to the operating room personnel of Khatam al-Anbia Hospital in the city of Zahedan.

\section{Author Contribution}

Aliakbar Keykha: data collection and compilation of the paper

Gholamali Dashti: data collection and assistance in compilation of the paper

Masoum Khoshfetrat: careful editing and revision of the paper

Faranak Beirami: participation in the implementation of research and supervision over data collection

Fahimeh Shirazian: participation in research implementation

\section{References}

Ayatollahi, V., Behdad, S., Hatami, M., Moshtaghiun, H., \& Baghianimoghadam, B. (2012). Comparison of peritonsillar infiltration effects of ketamine and tramadol on post tonsillectomy pain: A double-blinded randomized placebo-controlled clinical trial. Croatian Medical Journal, 53(2), 155-161. https://doi.org/10.3325/cmj.2012.53.155 PMID:22522994

Aydin, O. N., Ugur, B., Özgun, S., Eyigör, H., \& Copcu, O. (2007). Pain prevention with intraoperative ketamine in outpatient children undergoing tonsillectomy or tonsillectomy and adenotomy. Journal of Clinical Anesthesia, 19(2), 115-119. https:// doi.org/10.1016/j.jclinane.2006.06.003 PMID:17379123

Canbay, O., Celebi, N., Uzun, S., Şahin, A., Celiker, V., \& Aypar, U. (2008). Topical ketamine and morphine for post-tonsillectomy pain. European Journal of Anaesthesiology, 25(4), 287-292. https://doi.org/10.1017/S026502150700316X PMID: $\underline{18186954}$ 
Carlton, S. M., \& Coggeshall, R. E. (1999). Inflammation-induced changes in peripheral glutamate receptor populations. Brain Research, 820(1-2), 63-70. https://doi.org/ 10.1016/S0006-8993(98)01328-6 PMID:10023031

Carlton, S. M., Zhou, S., \& Coggeshall, R. E. (1998). Evidence for the interaction of glutamate and NK1 receptors in the periphery. Brain Research, 790(1-2), 160-169. https://doi.org/10.1016/S0006-8993(97)01471-6 PMID:9593874

Dal, D., Celebi, N., Elvan, E. G., Celiker, V., \& Aypar, U. (2007). The efficacy of intravenous or peritonsillar infiltration of ketamine for postoperative pain relief in children following adenotonsillectomy. Paediatric Anaesthesia, 17(3), 263-269. https://doi.org/10.1111/j. 1460-9592.2006.02095.x PMID:17263742

Eghbal, M. H., Taregh, S., Amin, A., \& Sahmeddini, M. A. (2013). Ketamine improves postoperative pain and emergence agitation following adenotonsillectomy in children. A randomized clinical trial. Middle East Journal of Anaesthesiology, 22(2), 155-160. PMID:24180163

Elhakim, M., Khalafallah, Z., El-Fattah, H. A., Farouk, S., \& Khattab, A. (2003). Ketamine reduces swallowing-evoked pain after paediatric tonsillectomy. Acta Anaesthesiologica Scandinavica, 47(5), 604-609. https://doi.org/10.1034/j.1399-6576.2003.00111.x PMID:12699521

Fazi, L., Jantzen, E. C., Rose, J. B., Kurth, C. D., \& Watcha, M. F. (2001). A comparison of oral clonidine and oral midazolam as preanesthetic medications in the pediatric tonsillectomy patient. Anesthesia and Analgesia, 92(1), 56-61. https://doi.org/ 10.1097/00000539-200101000-00011 PMID:11133600

Giannoni, C., White, S., Enneking, F. K., \& Morey, T. (2001). Ropivacaine with or without clonidine improves pediatric tonsillectomy pain. Archives of Otolaryngology-Head \& Neck Surgery, 127(10), 1265-1270. https://doi.org/10.1001/archotol.127.10.1265 PMID:11587610

Hamunen, K., \& Kontinen, V. (2005). Systematic review on analgesics given for pain following tonsillectomy in children. Pain, 117(1-2), 40-50. https://doi.org/10.1016/ j.pain.2005.05.012 PMID:16109456

Hanss, J., Nowak, C., Decaux, A., Penon, C., \& Bobin, S. (2011). Outpatient tonsillectomy in children: A 7-year experience. European Annals of Otorhinolaryngology, Head and Neck Diseases, 128(6), 283-289. https://doi.org/10.1016/j.anorl.2011.05.003 PMID: 21955462

Hosseini Jahromi, S. A., Hosseini Valami, S. M., \& Hatamian, S. (2012). Comparison between effect of lidocaine, morphine and ketamine spray on post-tonsillectomy pain in children. Anesthesiology and Pain Medicine, 2(1), 17-21. https://doi.org/10.5812/ aapm.4092 PMID:24223328

Javid, M. J., \& Khademian, G. (2016). Dissociative conscious sedation versus airway regional blocks in patients with predicted difficult airway: Advantages and disadvantages. Archives of Anesthesiology and Critical Care, 2(1), 161-164.

Javid, M. J., Hajijafari, M., Hajipour, A., Makarem, J., \& Khazaeipour, Z. (2012). Evaluation of a low dose ketamine in post tonsillectomy pain relief: A randomized trial comparing intravenous and subcutaneous ketamine in pediatrics. Anesthesiology and Pain Medicine, 2(2), 85-89. https://doi.org/10.5812/aapm.4399 PMID:24223344

Kimiaei Asadi, H., Nikooseresht, M., Noori, L., \& Behnoud, F. (2016). The effect of administration of ketamine and paracetamol versus paracetamol singly on postoperative pain, nausea and vomiting after pediatric adenotonsillectomy. 
Anesthesiology and Pain Medicine, 6(1), e31210. https://doi.org/10.5812/aapm.31210 PMID:27110529

Kimiaei Asadi, H., Nikooseresht, M., Noori, L., \& Behnoud, F. (2016). The effect of administration of ketamine and paracetamol versus paracetamol singly on postoperative pain, nausea and vomiting after pediatric adenotonsillectomy. Anesthesiology and Pain Medicine, 6(1), e31210. https://doi.org/10.5812/aapm.31210 PMID:27110529

Marret, E., Flahault, A., Samama, C. M., Bonnet, F., \& Bonnet, F. (2003). Effects of postoperative, nonsteroidal, antiinflammatory drugs on bleeding risk after tonsillectomy: Meta-analysis of randomized, controlled trials. The Journal of the American Society of Anesthesiologists, 98(6), 1497-1502. https://doi.org/ 10.1097/00000542-200306000-00030 PMID:12766664

Møiniche, S., Rømsing, J., Dahl, J. B., \& Tramèr, M. R. (2003). Nonsteroidal antiinflammatory drugs and the risk of operative site bleeding after tonsillectomy: A quantitative systematic review. Anesthesia and Analgesia, 96(1), 68-77. https://doi.org/ 10.1213/00000539-200301000-00015 PMID:12505926

O'Flaherty, J. E., \& Lin, C. X. (2003). Does ketamine or magnesium affect posttonsillectomy pain in children? Paediatric Anaesthesia, 13(5), 413-421. https:// doi.org/10.1046/j.1460-9592.2003.01049.x PMID:12791115

Pirzadeh, A., Mohammadi, M.-A., Allaf-Akbari, S., \& Entezariasl, M. (2012). The effect of ketamine on posttonsillectomy pain in children: A clinical trial. Iranian Journal of Otorhinolaryngology, 24(66), 23-28. PMID:24303381

Safavi, M., Honarmand, A., \& Atari, M. (2009). The pre-emptive analgesic effect of peritonsillar infiltration of ketamine for postoperative pain relief in children following tonsillectomy. A randomized, double-blind, placebo-controlled study. Journal of Iranian Society of Aanesthesiology and Intensive Care, 30(63-64), 45-53.

Shoar, S., Esmaeili, S., \& Safari, S. (2012). Pain management after surgery: A brief review. Anesthesiology and Pain Medicine, 1(3), 184-186. https://doi.org/10.5812/kowsar. 22287523.3443 PMID:24904790

Slatkin, N. E., \& Rhiner, M. (2003). Topical ketamine in the treatment of mucositis pain. Pain Medicine, 4(3), 298-303. https://doi.org/10.1046/j.1526-4637.2003.03032.x PMID: $\underline{12974832}$

Warncke, T., Jørum, E., \& Stubhaug, A. (1997). Local treatment with the N-methyl-Daspartate receptor antagonist ketamine, inhibit development of secondary hyperalgesia in man by a peripheral action. Neuroscience Letters, 227(1), 1-4. https:// doi.org/10.1016/S0304-3940(97)00263-2 PMID:9178844 